\title{
Women Build Long Bones With Less Cortical Mass Relative to Body Size and Bone Size Compared With Men
}

\author{
Karl J. Jepsen PhD, Erin M. R. Bigelow MS, \\ Stephen H. Schlecht PhD
}

Published online: 18 February 2015

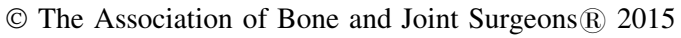

\begin{abstract}
Background The twofold greater lifetime risk of fracturing a bone for white women compared with white men and black women has been attributed in part to differences in how the skeletal system accumulates bone mass during growth. On average, women build more slender long bones with less cortical area compared with men. Although slender bones are known to have a naturally lower cortical area compared with wider bones, it remains unclear whether the relatively lower cortical area of women is consistent with their increased slenderness or is reduced
\end{abstract}

Research reported in this publication was supported by the National Institutes of Health under award numbers AR44927 (KJJ) and AR065424 (KJJ).

The content is solely the responsibility of the authors and does not necessarily represent the official views of the National Institutes of Health.

All ICMJE Conflict of Interest Forms for authors and Clinical Orthopaedics and Related Research ${ }^{\circledR}$ editors and board members are on file with the publication and can be viewed on request. Clinical Orthopaedics and Related Research ${ }^{\mathbb{R}}$ neither advocates nor endorses the use of any treatment, drug, or device. Readers are encouraged to always seek additional information, including FDA-approval status, of any drug or device prior to clinical use. Each author certifies that his or her institution approved or waived approval for the human protocol for this investigation and that all investigations were conducted in conformity with ethical principles of research. Each author certifies that his or her institution approved the animal protocol for this investigation and that all investigations were conducted in conformity with ethical principles of research.

This work was performed at the University of Michigan, Ann Arbor, MI, USA.

K. J. Jepsen ( $\square$ ), E. M. R. Bigelow, S. H. Schlecht Department of Orthopaedic Surgery, University of Michigan, 109 Zina Pitcher Place, Room 2001 BSRB, Ann Arbor, MI 48109, USA

e-mail: kjepsen@med.umich.edu beyond that expected for the sex-specific differences in bone size and body size. Whether this sexual dimorphism is consistent with ethnic background and is recapitulated in the widely used mouse model also remains unclear.

Questions/purposes We asked (1) do black women build bones with reduced cortical area compared with black men; (2) do white women build bones with reduced cortical area compared with white men; and (3) do female mice build bones with reduced cortical area compared with male mice?

Methods Bone strength and cross-sectional morphology of adult human and mouse bone were calculated from quantitative $\mathrm{CT}$ images of the femoral midshaft. The data were tested for normality and regression analyses were used to test for differences in cortical area between men and women after adjusting for body size and bone size by general linear model (GLM).

Results Linear regression analysis showed that the femurs of black women had $11 \%$ lower cortical area compared with those of black men after adjusting for body size and bone size (women: mean $=357.7 \mathrm{~mm}^{2} ; 95 \%$ confidence interval [CI], 347.9-367.5 $\mathrm{mm}^{2}$; men: mean $=400.1 \mathrm{~mm}^{2}$; 95\% CI, $391.5-408.7 \mathrm{~mm}^{2}$; effect size $=1.2 ; \mathrm{p}<0.001$, GLM). Likewise, the femurs of white women had $12 \%$ less cortical area compared with those of white men after adjusting for body size and bone size (women: mean $=350.1 \mathrm{~mm}^{2} ; 95 \%$ CI, 340.4-359.8 $\mathrm{mm}^{2}$; men: mean $=394.3 \mathrm{~mm}^{2} ; 95 \% \mathrm{CI}$, $386.5-402.1 \mathrm{~mm}^{2}$; effect size $=1.3 ; \mathrm{p}<0.001$, GLM). In contrast, female and male femora from recombinant inbred mouse strains showed the opposite trend; femurs from female mice had a $4 \%$ larger cortical area compared with those of male mice after adjusting for body size and bone size (female: mean $=0.73 \mathrm{~mm}^{2} ; 95 \%$ CI, $0.71-0.74 \mathrm{~mm}^{2}$; male: mean $=0.70 \mathrm{~mm}^{2} ; 95 \% \mathrm{CI}, 0.68-0.71 \mathrm{~mm}^{2}$; effect size $=0.74 ; p=0.04$, GLM). 
Conclusions Female femurs are not simply a more slender version of male femurs. Women acquire substantially less mass (cortical area) for their body size and bone size compared with men. Our analysis questions whether mouse long bone is a suitable model to study human sexual dimorphism.

Clinical Relevance Identifying differences in the way bones are constructed may be clinically important for developing sex-specific diagnostics and treatment strategies to reduce fragility fractures.

\section{Introduction}

Women show a two- to threefold greater lifetime risk of sustaining a fragility fracture compared with men [3, 5, 17]. The sex-specific difference in fracture susceptibility has been attributed, in part, to the sexually dimorphic skeleton, which is thought to arise from differential expression of sex hormones during puberty $[16,28]$. Our knowledge of sexual dimorphism is based largely on a comparison of group means. On average, women construct bones that are more slender (narrow relative to length) and less strong compared with those of men, even after adjusting for body size [18]. However, men and women also show tremendous variation in bone size within their own sex group and this variation far exceeds the differences between sex groups [31]. One question that has not been fully answered is whether female bones are just a more slender version of male bones or whether men and women build bones in fundamentally different ways. Knowing the outcome of this question is clinically meaningful, because fundamental differences in the way the skeleton is constructed may be important for developing sex-specific diagnostic and treatment strategies to reduce fragility fractures.

To answer whether men and women build bones in fundamentally different ways, we conducted an analysis that looked beyond group means by studying how bone strength parameters differ across the entire male and female populations. Testing for differences in the way men and women build bones was facilitated by taking the complex adaptive nature of the skeletal system into consideration. Prior work revealed predictable patterns in the way the skeletal system coordinately adjusts multiple traits simultaneously to establish whole bone mechanical function (homeostasis) [13, 14, 31, 32]. A consequence of the pattern is that slender bones are built differently (ie, have a different set of traits) compared with robust bones. When viewed across a population, the coordinately adjusted traits present as simple linear regressions (Fig. 1), allowing us to refocus the primary question as: "Do men and women coordinately adjust their traits to establish whole bone mechanical function in similar ways?" We tested for sexspecific differences in the way three diaphyseal bone traits (robustness, cortical area, tissue mineral density) covaried in a collection of adult human femurs. We chose these particular traits based on our prior research, which showed how cortical area and tissue mineral density vary relative to the natural variation in bone robustness [13]. We studied the natural variation in robustness as a natural perturbation experiment, asking how the skeletal system coordinately adjusted traits to make slender (narrow relative to length) bones as stiff and strong as robust (wide relative to length) bones [14]. These three traits represent the minimum number of traits needed to systematically evaluate differences in how men and women coordinately adjust traits to establish whole bone mechanical function [26, 27]. One advantage of conducting a regression analysis, in addition to a comparison of group means, was that we were also able to test whether the difference in the way men and women coordinately adjust traits is uniform (change in yintercept) or nonuniform (change in slope) across the population (Fig. 1). A uniform versus nonuniform difference may provide novel clues as to whether the biologic factors regulating the functional adaptation process act in similar ways across the male and female populations. These considerations may be important for developing sexspecific diagnostics and treatments.

To test whether men and women build bones in fundamentally different ways, we compared cortical area between men and women after adjusting for body size and bone robustness. We examined individuals of black and white ethnicities because of their availability in the Hamann-Todd Osteological Collection and because white women show a twofold greater risk of fracturing compared with white men, whereas black women show a similar risk of fracturing compared with black men [3, 5, 17]. We separated our analysis by ethnicity given known differences in bone structure between black and white women [4] and to determine if the sex differences in fracture risk can be explained in part based on ethnic differences in sexual dimorphism. Finally, because mouse models are widely used in musculoskeletal biology research [10, 22], we conducted parallel studies in mouse bone to test whether mice show a sexually dimorphic skeleton consistent with that of humans.

We asked (1) do black women build bones with reduced cortical area compared with black men; (2) do white women build bones with reduced cortical area compared with white men; and (3) do female mice build bones with reduced cortical area compared with male mice? 

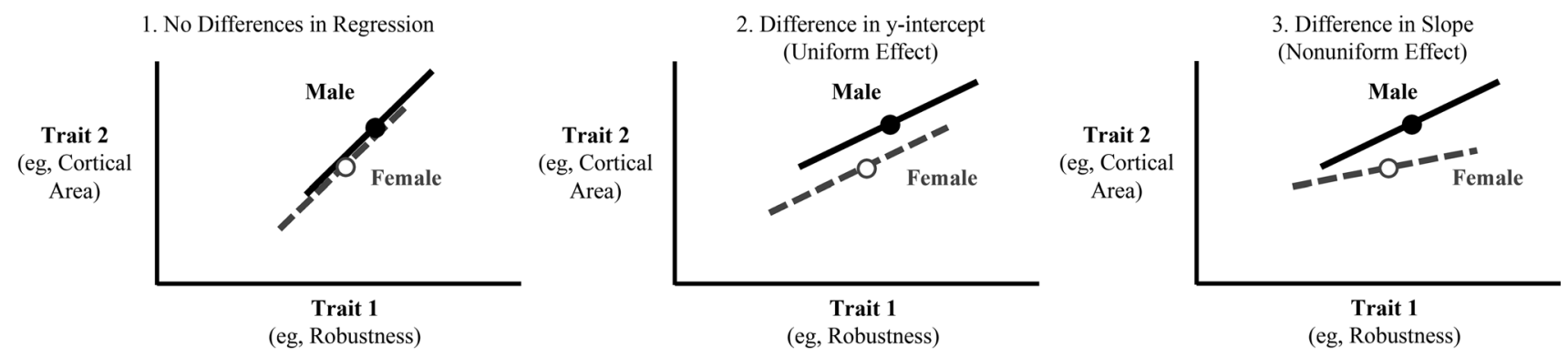

Fig. 1 Two populations can show significant differences in group means for two traits; however, linear regression analysis revealed population-level differences in how the system coordinately adjusts these traits during the functional adaptation process. A comparison of linear regressions between men and women would be expected to reveal whether (1) men and women coordinately adjust traits in

\section{Materials and Methods}

\section{Study Design}

To test whether men and women build bones in fundamentally different ways, we examined femurs from the skeletal remains of individuals included in the HamannTodd Osteological Collection (Cleveland, OH, USA). Our sample populations consisted of 63 black men, 52 black women, 74 white men, and 52 white women who had ranged in age between 20 and 35 years. Sample size was determined based on availability of individuals within the young adult age range. Only individuals with no observable skeletal pathology were included. Body height and weight were documented at the time of autopsy. A parallel analysis was conducted using the femurs of adult (16-weekold) male and female AXB/BXA recombinant inbred (RI) mouse strains to test whether mouse femurs showed similar sex-specific differences as human femurs. The panel consisted of $20 \mathrm{AXB} / \mathrm{BXA}$ RI strains (20 female strains, 20 male strains) purchased from the Jackson Laboratories (Bar Harbor, ME, USA). All mice were handled in accordance with approved protocols approved by the Institutional Animal Care and Use Committee. The analyses were based on the mean trait values for each strain, which were calculated using approximately $10 \mathrm{mice} / \mathrm{strain} / \mathrm{sex}$. The particular mouse intercross was examined because the parental strains, A/J and C57BL/6J (B6), show a similar range in femoral robustness as human femurs $[11,15]$. Furthermore, the long bones from the AXB/BXA RI strains coordinately adjust morphologic and compositional traits in the same way as humans [14]. The mouse and human bone data have been reported previously [14, 26, 27], but our study analyzed the data in a novel way.

For human femora, bone length was measured from the proximal femoral head to the distal condyle using a similar ways (ie, no difference in the regressions); (2) there is a uniform offset in the degree to which one trait is adjusted relative to another (ie, a difference in the y-intercept); or (3) there is a nonuniform offset in the degree to which one trait is adjusted relative to another (ie, a difference in slope).

stadiometer [27]. The femoral midshaft was imaged using an XCT 2000 peripheral quantitative CT system (Stratec Medizentechnik, Pforzheim, Germany) as described previously [27]. Images were acquired at $0.10 \mathrm{~mm} \times 0.10$ $\mathrm{mm}$ in-plane pixel size. Image quality and consistency were maintained daily by scanning a calibration standard with known densities. Total cross-sectional area, cortical area, mean gray value, and the rectangular area moments of inertia about the anteroposterior $\left(\mathrm{I}_{\mathrm{AP}}\right)$ and mediolateral $\left(\mathrm{I}_{\mathrm{ML}}\right)$ axes were quantified, as described previously [27]. Robustness, which is a standard term used to describe the amount of transverse expansion relative to longitudinal growth [19, 24], was calculated as total area/length. Cortical tissue mineral density, which is proportional to tissue modulus [13], was calculated from the mean gray value using the calibration standard. A bone strength index was calculated as cortical tissue mineral density $\times$ rectangular moment of inertia about the mediolateral axis $\left(\mathrm{I}_{\mathrm{ML}}\right)$, which correlates with the bending stiffness and strength measured for cadaveric long bones loaded to failure in four-point bending [26].

For mouse femora, length was measured using a digital caliper (0.01-mm resolution). Middiaphyseal cross-sectional morphology and tissue mineral density were measured using micro-CT as described previously [14]. Cross-sectional traits included cortical area, marrow area, total area, and polar moment of inertia (J). Robustness was calculated as total area/length. Cortical tissue mineral density was calculated by converting the gray scale output of bone voxels in Hounsfield units (HU) to mineral values $(\mathrm{mg} / \mathrm{cc} \mathrm{HA}$, where $\mathrm{HA}=$ hydroxyapatite) using a calibration phantom containing air, water, and hydroxyapatite mimicker (SB3: Gammex RMI, Middleton, WI, USA). Unlike human long bones, whole bone stiffness and maximum load of mouse femurs were measured directly by subjecting the femora to whole bone four-point bending tests [14]. 

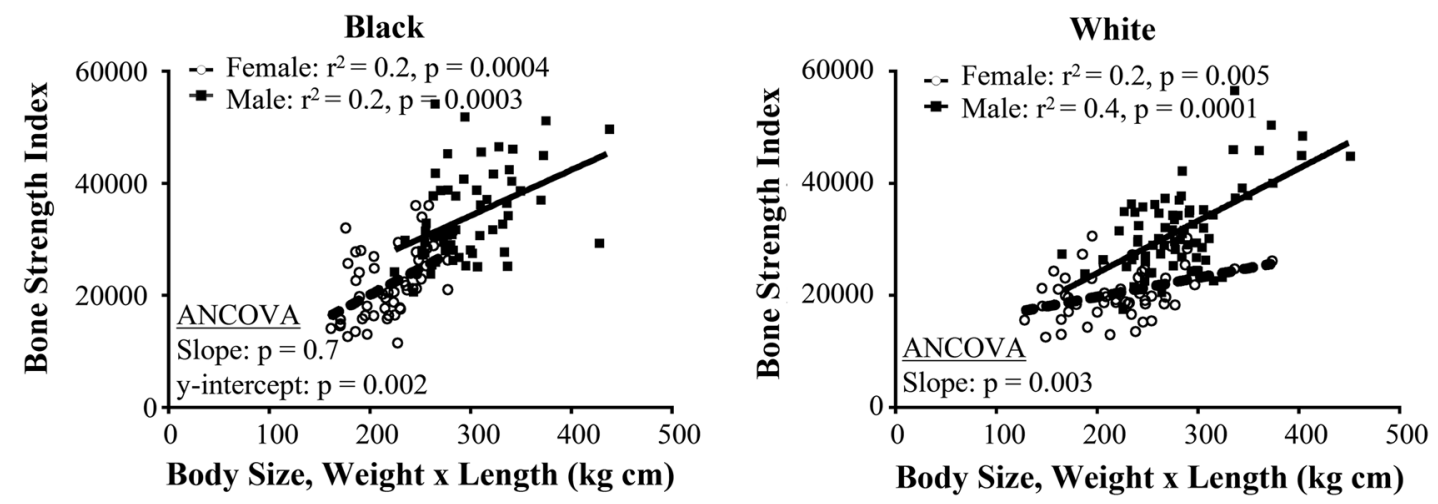

\begin{tabular}{|rccc|}
\hline & $\begin{array}{c}\text { Bone Strength } \\
\text { Index, Adjusted }\end{array}$ & $\begin{array}{c}\text { Percent } \\
\text { Difference }\end{array}$ & p Value \\
\cline { 2 - 4 } Black Female & $25,522 \pm 7987$ & $19 \%$ & 0.0019 \\
Black Male & $30,945 \pm 7729$ & & \\
White Female & $22,892 \pm 6062$ & $27 \%$ & 0.0001 \\
White Male & $29,986 \pm 5905$ & & \\
RI Female & $25.0 \pm 3.3$ & $10 \%$ & 0.04 \\
RI Male & $22.5 \pm 3.3$ & & \\
\hline \hline
\end{tabular}

GLM: Body size as a covariate

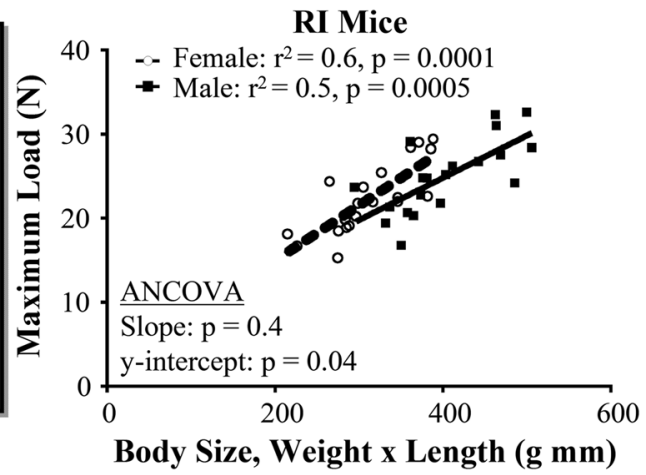

Fig. 2 The bone strength index $(\mathrm{BSI})=$ rectangular moment of inertia about the mediolateral axis $\left(\mathrm{I}_{\mathrm{ML}}\right) \times$ cortical tissue mineral density; $\mathrm{mm}^{4} \mathrm{mg} \mathrm{HA}$ ) increased with body size for both black and white cohorts. Maximum load of the femur increased with body size for adult male and female RI mice. Significant differences in the slope

\section{Statistical Analyses}

Because the data were normally distributed $(\mathrm{p}>0.05$, Shapiro-Wilk normality test), parametric tests were conducted to address our questions. Linear regression analysis was used to determine whether men and women build bone in fundamentally different ways. The same analyses were conducted for mouse femora. First, we tested whether men build stronger femurs relative to body size compared with women by regressing bone strength index against body size and comparing the slope and y-intercept by analysis of covariance (ANCOVA). This was done for white and black populations separately. Body size was calculated as body weight $\times$ bone length, which is an approximation of the bending load applied to the femur [23, 30]. We also tested whether men build a wider, more robust femur relative to body size compared with women by regressing robustness against body size and comparing the slope and y-intercept by ANCOVA. Second, we tested whether men build femurs with more cortical area and cortical tissue mineral density compared with women by regressing cortical area and cortical tissue mineral density against robustness and comparing the slope and y-intercept by ANCOVA. Third, group mean differences between men and women were or $y$-intercept of the linear regressions for males and females were determined by ANCOVA. Results of the group mean comparison using GLM are shown (box). Adjusted means and SDs are shown in the box. $\mathrm{HA}=$ hydroxyapatite; $\mathrm{I}_{\mathrm{ML}}=$ mediolateral; $\mathrm{RI}=$ recombinant inbred.

calculated for each outcome variable using a general linear model (GLM). For bone strength and robustness, the only covariate was body size. We also tested for differences in bone strength with body size and robustness as covariates to determine how much of the sex differences in bone strength was explained by the differences in robustness. Covariates for cortical area and cortical tissue mineral density included body size and robustness because cortical area naturally correlates positively with robustness, whereas cortical tissue mineral density correlates negatively with robustness when viewed across a population [13, 27]. Effect sizes were reported as Cohen's $d$ and calculated as the difference between the two means, slopes, or y-intercepts divided by the pooled SD for that parameter.

\section{Results}

Femoral strength increased with body size, as expected, for the human and mouse populations (Fig. 2). The y-intercept for the regression was significantly lower for black women compared with black men (Women: y-intercept $=$ $1248 \mathrm{~mm}^{4} \mathrm{mg} \mathrm{HA} ; 95 \%$ confidence interval [CI], -9715 to $12211 \mathrm{~mm}^{4} \mathrm{mg}$ HA; men: y-intercept $=9768 \mathrm{~mm}^{4} \mathrm{mg}$ 
HA; $95 \% \mathrm{CI},-2815$ to $22352 \mathrm{~mm}^{4} \mathrm{mg} \mathrm{HA}$; effect size $=1.4 ; p=0.002$, ANCOVA), indicating the sexspecific difference in femoral strength was uniform across the population. In contrast, the slope of the linear regressions was significantly reduced for white women compared with white men (women: slope $=34.0 \mathrm{~mm}^{4} \mathrm{mg} \mathrm{HA} / \mathrm{kg}$ $\mathrm{cm} ; 95 \%$ CI, $10.7-57.3 \mathrm{~mm}^{4} \mathrm{mg} \mathrm{HA} / \mathrm{kg} \mathrm{cm}$; men: slope $=93.1 \mathrm{~mm}^{4} \mathrm{mg} \quad \mathrm{HA} / \mathrm{kg} \mathrm{cm} ; \quad 95 \%$ CI, 64.6$121.7 \mathrm{~mm}^{4} \mathrm{mg} \mathrm{HA} / \mathrm{kg} \mathrm{cm}$; effect size $=4.5 ; \mathrm{p}=0.003$, ANCOVA), indicating that the relationship between femoral strength and body size was more similar for smaller white men and women compared with larger white men and women. Mice showed the opposite effect as humans with female mice exhibiting significantly greater femoral whole bone strength compared with males (female: y-intercept $=2.03 \mathrm{~N}$; $95 \% \mathrm{CI},-5.73$ to $9.78 \mathrm{~N}$; male: $\mathrm{y}$ intercept $=4.88 \mathrm{~N} ; 95 \% \mathrm{CI},-5.19$ to $14.95 \mathrm{~N}$; effect size $=0.66 ; p=0.04$, ANCOVA). A comparison of group mean differences was conducted using GLM to calculate the percent difference in these traits between men and women. Femoral strength relative to body size was $19 \%$ lower for black women compared with black men (women: mean $=25,522 \mathrm{mg} \mathrm{HA} \mathrm{mm}^{4} ; 95 \% \mathrm{CI}, 23,351-27,692 \mathrm{mg}$ $\mathrm{HA} \mathrm{mm}{ }^{4}$; men: mean $=30,945 \mathrm{mg} \mathrm{HA} \mathrm{mm} \mathrm{mm}^{4}$ 95\% CI, 29,036-32,854 mg HA $\mathrm{mm}^{4}$; effect size $=0.69$; $\mathrm{p}<0.001, \mathrm{GLM}) ; 27 \%$ lower for white women compared with white men (women: mean $=22,892 \mathrm{mg} \mathrm{HA} \mathrm{mm}$; 95\% CI, 21,244-24,540 mg HA mm ${ }^{4}$; men: mean = $29,986 \mathrm{mg}$ HA mm${ }^{4}$; $95 \% \mathrm{CI}, 28,640-31,331 \mathrm{mg}$ HA $\mathrm{mm}^{4}$; effect size $=1.19 ; \mathrm{p}<0.001$, GLM $) ;$ but $10 \%$ greater for female mice compared with male mice (female: mean $=25.0 \mathrm{~N} ; 95 \% \mathrm{CI}, 23.5-26.4 \mathrm{~N}$; male: mean $=$ $22.5 \mathrm{~N} ; \quad 95 \%$ CI, $21.0-23.9 \mathrm{~N}$; effect size $=0.74$; $\mathrm{p}=0.04, \mathrm{GLM})$. When adjusting femoral strength for both body size and robustness by GLM, black women showed a 9\% lower strength compared with black men (women: mean $=27,127 \mathrm{mg} \mathrm{HA} \mathrm{mm}{ }^{4} ; 95 \% \mathrm{CI}, 25,867-28,387 \mathrm{mg}$ $\mathrm{HA} \mathrm{mm}{ }^{4}$; men: mean $=29,620 \mathrm{mg} \mathrm{HA} \mathrm{mm}$; $95 \% \mathrm{CI}$, $28,514-30,725 \mathrm{mg}$ HA $\mathrm{mm}^{4}$; effect size $=0.55$; $\mathrm{p}=0.014$, GLM); white women showed $11 \%$ lower strength compared with white men (women: mean = $25,288 \mathrm{mg}$ HA mm${ }^{4}$; 95\% CI, 24,093-26,483 mg HA $\mathrm{mm}^{4}$; men: mean $=28,302 \mathrm{mg} \mathrm{HA} \mathrm{mm}{ }^{4} ; 95 \% \mathrm{CI}, 27,340$ $29,264 \mathrm{mg}$ HA mm${ }^{4}$; effect size $=0.70 ; \mathrm{p}<0.001$, GLM); and female mice showed $10 \%$ greater bone strength compared with male mice (female: mean $=24.9 \mathrm{~N} ; 95 \%$ CI, 23.7-26.1 N; male: mean $=22.6 \mathrm{~N}$; 95\% CI, 21.3$23.8 \mathrm{~N}$; effect size $=0.84 ; \mathrm{p}=0.024$, GLM). This adjusted analysis indicated that the sex-specific differences in robustness accounted for $52 \%$ to $59 \%$ of the differences in femoral strength between men and women.

Robustness increased with body size, except in white women (Fig. 3). The femora of black women were uniformly more slender compared with black men (women: y-intercept $=0.837 \mathrm{~mm} / \mathrm{kg} \mathrm{cm} ; \quad 95 \% \quad$ CI, $\quad 0.576-$ $1.098 \mathrm{~mm} / \mathrm{kg} \mathrm{cm}$; men: $y$-intercept $=1.043 \mathrm{~mm} / \mathrm{kg} \mathrm{cm}$; $95 \% \quad$ CI, $\quad 0.818-1.267 \mathrm{~mm} / \mathrm{kg} \mathrm{cm}$; effect size $=1.7$; $\mathrm{p}=0.04$, ANCOVA), whereas the femora of white women were also more slender compared with white men but this difference was nonuniform across the population (women: slope $=0.000013 \mathrm{~mm} / \mathrm{kg} \mathrm{cm} ; 95 \%$ CI, -0.00069 to $0.00072 \mathrm{~mm} / \mathrm{kg} \mathrm{cm}$; men: slope $=0.00096 \mathrm{~mm} / \mathrm{kg} \mathrm{cm}$; $95 \% \mathrm{CI}, 0.00042-0.00149 \mathrm{~mm} / \mathrm{kg} \mathrm{cm}$; effect size $=3.0$; $\mathrm{p}=0.03$, ANCOVA). In contrast, no differences in the slope (female: slope $=0.000104 \mathrm{~mm} / \mathrm{g} \mathrm{mm} ; 95 \% \mathrm{CI}$, -0.0000148 to $0.000223 \mathrm{~mm} / \mathrm{g} \mathrm{mm}$; male: slope $=$ $0.000122 \mathrm{~mm} / \mathrm{g} \mathrm{mm} ; 95 \% \mathrm{CI}, 0.0000127-0.000232 \mathrm{~mm} /$ $\mathrm{g} \mathrm{mm}$; effect size $=0.33 ; \mathrm{p}=0.8$, ANCOVA) or y-intercept (female: $\quad \mathrm{y}$-intercept $=0.0526 \mathrm{~mm} / \mathrm{g} \mathrm{mm} ; \quad 95 \% \quad \mathrm{CI}$, $0.0151-0.090 \mathrm{~mm} / \mathrm{g} \mathrm{mm}$; male: $\mathrm{y}$-intercept $=0.0451 \mathrm{~mm} /$ $\mathrm{g} \mathrm{mm} ; \quad 95 \%$ CI, $\quad 0.000587-0.0896 \mathrm{~mm} / \mathrm{g} \mathrm{mm}$; effect size $=0.38 ; \mathrm{p}=0.8$, ANCOVA) were found for the mice, suggesting that the sex difference in robustness was explained largely by the differences in body size. Group mean differences in robustness, after adjusting for body size, revealed that the femora of black women were $6 \%$ more slender relative to body size compared with black men (women: mean $=1.20 \mathrm{~mm}$; 95\% CI, 1.16-1.25 mm; men: mean $=1.28 \mathrm{~mm} ; 95 \%$ CI, $1.24-1.31 \mathrm{~mm}$; effect size $=0.45 ; \mathrm{p}=0.04$, GLM); the femora of white women were $10 \%$ more slender relative to body size compared with white men (women: mean $=1.18 \mathrm{~mm}$; 95\% CI, 1.14 $1.22 \mathrm{~mm}$; men: mean $=1.30 \mathrm{~mm} ; 95 \% \quad \mathrm{CI}, \quad 1.27$ $1.33 \mathrm{~mm}$; effect size $=0.93 ; \mathrm{p}<0.001$, GLM); and the femora of female mice were $1 \%$ more robust (not significant) compared with male mice (female: mean $=0.090 \mathrm{~mm} ; 95 \%$ CI, $0.084-0.097 \mathrm{~mm} ;$ male: mean $=0.089 \mathrm{~mm} ; \quad 95 \%$ CI, $0.082-0.096 \mathrm{~mm}$; effect size $=0.08 ; \mathrm{p}=0.82$, GLM).

As noted, only approximately half the difference in bone strength between men and women was explained by the sex-specific differences in robustness, meaning that other deficits remain to be found in the female skeleton. The femora of black and white women showed lower cortical area but greater cortical tissue mineral density compared with the femora of black and white men. Because cortical area is naturally lower (Fig. 4) and cortical tissue mineral density naturally higher (Fig. 5) in slender femora compared with robust femora, we wanted to know if the sexspecific differences in the two traits were adjusted to the levels expected given baseline differences in robustness between men and women. A comparison of group mean differences for cortical area with body size and robustness as covariates showed that the femora of black women exhibited an $11 \%$ lower cortical area compared with black men (women: mean $=357.7 \mathrm{~mm}^{2}$; 95\% CI, 347.9-367.5 mm² 


\section{Black}

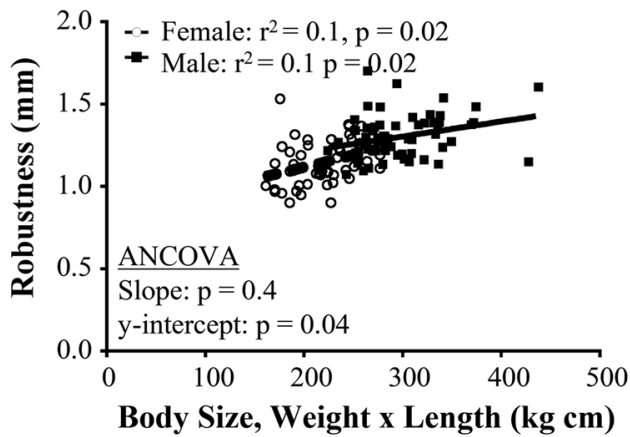

\begin{tabular}{|rccc|}
\hline & $\begin{array}{c}\text { Robustness, } \\
\text { Adjusted }\end{array}$ & $\begin{array}{c}\text { Percent } \\
\text { Difference }\end{array}$ & p Value \\
\cline { 2 - 4 } Black Female & $1.20 \pm 0.16$ & $6 \%$ & 0.04 \\
Black Male & $1.28 \pm 0.16$ & & \\
White Female & $1.18 \pm 0.13$ & $10 \%$ & 0.0001 \\
White Male & $1.30 \pm 0.13$ & & \\
& & $1 \%$ & 0.82 \\
RI Female & $0.090 \pm 0.015$ & & \\
RI Male & $0.089 \pm 0.015$ & & \\
\hline
\end{tabular}

GLM: Body size as a covariate

Fig. 3 Femoral robustness (total cross-sectional area/length) increased with body size for black women and men, white women and men, and female and male RI mice. Significant differences in the slope or $y$-intercept of the linear regressions for males and females

men: mean $=400.1 \mathrm{~mm}^{2} ; 95 \%$ CI, $391.5-408.7 \mathrm{~mm}^{2}$; effect size $=1.2 ; \mathrm{p}<0.001$, GLM). Likewise, a comparison of group mean differences for cortical area with body size and robustness as covariates showed that the femora of white women exhibited a $12 \%$ lower cortical area compared with white men (women: mean $=350.1$ $\mathrm{mm}^{2} ; 95 \%$ CI, $340.4-359.8 \mathrm{~mm}^{2}$; men: mean $=394.3$ $\mathrm{mm}^{2} ; \quad 95 \%$ CI, $\quad 386.5-402.1 \mathrm{~mm}^{2}$; effect size $=1.3$; $\mathrm{p}<0.001$, GLM). In contrast, female mice showed a $4 \%$ greater cortical area relative to body size and robustness compared with male mice (female: mean $=0.73 \mathrm{~mm}^{2}$; 95\% CI, 0.71-0.74 $\mathrm{mm}^{2}$; male: mean $=0.70 \mathrm{~mm}^{2} ; 95 \%$ CI, 0.68-0.71 $\mathrm{mm}^{2}$; effect size $=0.74 ; \mathrm{p}=0.04$, GLM). For cortical tissue mineral density, a comparison of group means showed that the femora of black women exhibited a $1.3 \%$ greater cortical tissue mineral density than expected for their body size and robustness compared with black men (women: mean $=1287 \mathrm{mg} \mathrm{HA} ; 95 \%$ CI, 1280 1294 mg HA; men: mean $=1270$ mg HA; 95\% CI, 1264 $1276 \mathrm{mg} \mathrm{HA}$; effect size $=0.70 ; \mathrm{p}=0.002$, GLM). White women exhibited a $0.6 \%$ greater cortical tissue mineral density than expected for their body size and robustness compared with men, but this difference was not significant (women: mean $=1253 \mathrm{mg} \mathrm{HA} ; 95 \% \mathrm{CI}, 1244-1262 \mathrm{mg}$

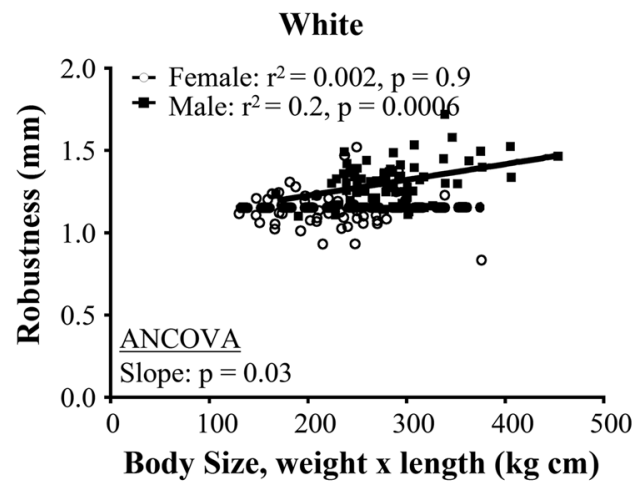

RI Mice

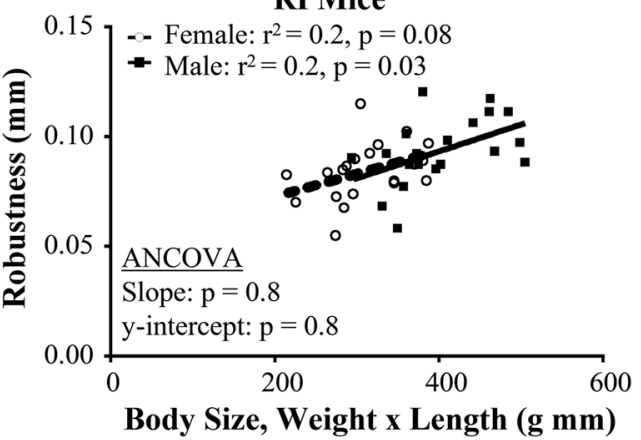

were determined by ANCOVA. Results of the group mean comparison using GLM are shown (box). Adjusted means and SDs are shown in the box. RI = recombinant inbred.

HA; men: mean $=1246 \mathrm{mg} \mathrm{HA}$; 95\% CI, 1239-1253 mg $\mathrm{HA}$; effect size $=0.22 ; \mathrm{p}=0.27$, GLM). The femora of female mice showed a $2.2 \%$ greater cortical tissue mineral density than expected for their body size and robustness compared with male mice (female: mean $=1315 \mathrm{mg} \mathrm{HA}$; 95\% CI, 1304-1326 mg HA; male: mean $=1286$ mg HA; $95 \%$ CI, $1275-1296 \mathrm{mg} \quad \mathrm{HA}$; effect size $=1.16$; $\mathrm{p}=0.003, \mathrm{GLM})$.

\section{Discussion}

The motivation for this study was to further understand the bone structural parameters that contribute to sex and ethnic differences in the risk of sustaining a fragility fracture $[5,17]$. Prior work showed that women build more slender bones with less cortical area compared with men, even after adjusting for body size [7, 18]. Our prior research has shown that slender bones have a lower cortical area compared with wider, more robust bones [13]. It was unclear whether the lower cortical area reported in the long bones of women was consistent with them having a more slender structure. The goal of our study was to test whether men and women build femurs in fundamentally different ways. 


\section{Black}

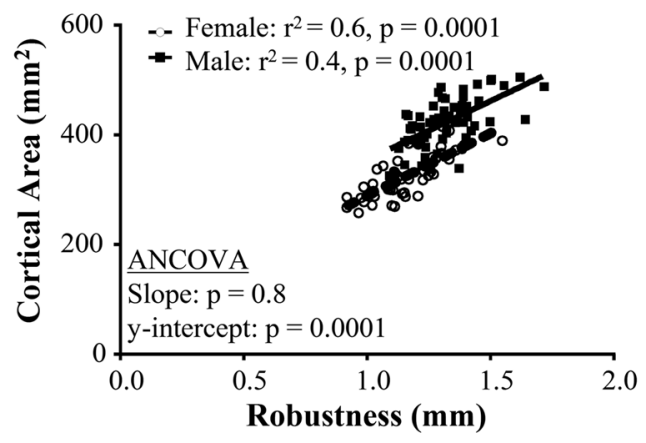

\begin{tabular}{|rccc|}
\hline & $\begin{array}{c}\text { Cortical } \\
\text { Area, Adjusted }\end{array}$ & $\begin{array}{c}\text { Percent } \\
\text { Difference }\end{array}$ & p Value \\
\cline { 2 - 4 } Black Female & $357.7 \pm 36.2$ & $11 \%$ & 0.0001 \\
Black Male & $400.1 \pm 34.9$ & & \\
White Female & $350.1 \pm 35.7$ & $12 \%$ & 0.0001 \\
White Male & $394.3 \pm 34.3$ & & \\
RI Female & $0.73 \pm 0.04$ & $4 \%$ & 0.04 \\
RI Male & $0.70 \pm 0.04$ & & \\
\hline \hline
\end{tabular}

GLM: Body size and robustnesss as covariates

Fig. 4 Femoral cortical area increased significantly with body size for black women and men, white women and men, and female and male RI mice. Significant differences in the slope or y-intercept of the linear regressions for males and females were determined by

Our analyses confirmed these prior reports that women have reduced whole bone strength and more slender bones compared to men [7, 18]. Furthermore, our analyses found that (1) black women have significantly lower cortical area than black men after adjusting for both body size and bone size; and that (2) white women also have significantly lower cortical area than white men after adjusting for both body size and bone size. Thus, our analyses identified an important structural deficit in women that has not been previously reported. Because mice are often used in musculoskeletal biology research, we also tested whether sexual dimorphism in mice was consistent with humans. Our analysis of a panel of recombinant mouse strains revealed that in comparison to male mice, female mice had femurs that were not different in terms of robustness and had a higher cortical area and tissue mineral density after adjusting for body size and bone size. Together, these structural factors resulted in female mice having a greater whole bone strength compared with male mice. This outcome is inconsistent with the dimorphism observed for human femurs.

A primary limitation of this study was that the analyses were conducted on the bones of adults between 20 and 35 years of age. Assessing bone structure at an adult
White

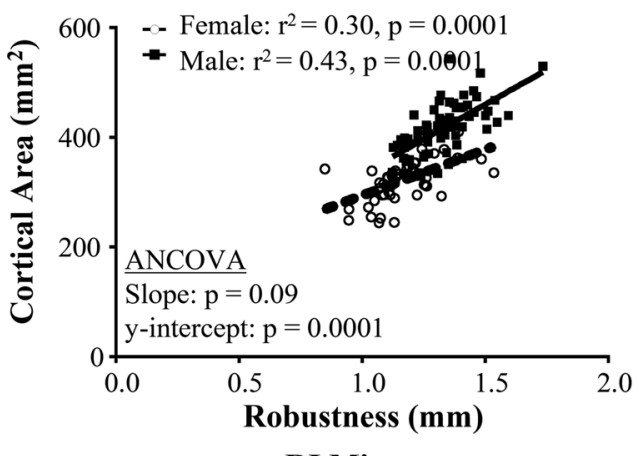

RI Mice

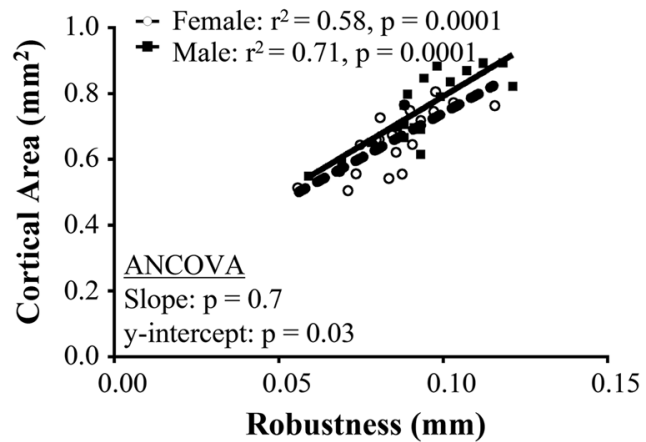

ANCOVA. Results of the group mean comparison using GLM are shown (box). Adjusted means and SDs are shown in the box. $\mathrm{RI}=$ recombinant inbred.

timeframe was a strategic decision, because any differences found from this analysis could be used to direct studies examining (1) how the structural deficit in women arises during growth; and (2) the impact that the structural deficit has on skeletal aging. A theoretical analysis indicated that having a slender bone combined with a lower than expected cortical area severely affected the amount of periosteal expansion needed to maintain strength with aging [12]. Thus, the results of our current study provide the motivation to incorporate these structural features into clinical studies and to refocus the question from whether women show a lower periosteal expansion with aging on an absolute basis compared with men [29] to whether there are factors impairing periosteal expansion in women beyond that expected for having more slender bones combined with lower than expected cortical area. The linear regressions for the human data showed $r^{2}$ values ranging from 0.03 to 0.6 , which is entirely consistent with those reported in the literature for interactions among traits or for associations between similar traits and age [1, 20, 25]. The human data are certainly more variable than the mouse data, and this should be expected. Further research is needed to better understand how these traits can be related to measures of body size. Only measures of body mass and 
Black

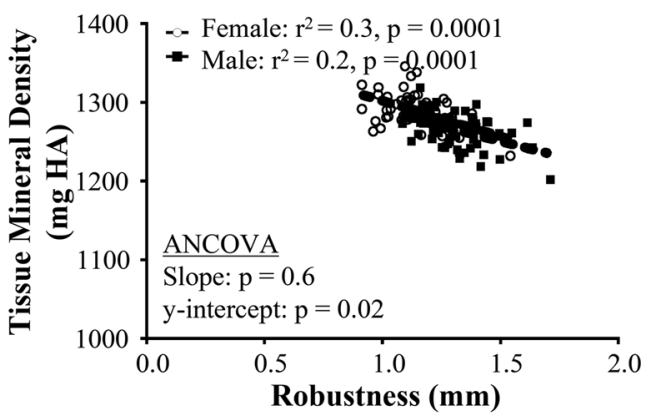

\begin{tabular}{|rccc|}
\hline & $\begin{array}{c}\text { Tissue Mineral } \\
\text { Density, Adjusted }\end{array}$ & $\begin{array}{c}\text { Percent } \\
\text { Difference }\end{array}$ & p Value \\
\cline { 2 - 4 } Black Female & $1287 \pm 25$ & $1 \%$ & 0.002 \\
Black Male & $1270 \pm 24$ & & \\
White Female & $1253 \pm 32$ & $1 \%$ & 0.27 \\
White Male & $1246 \pm 31$ & & \\
RI Female & $1315 \pm 25$ & $2 \%$ & 0.003 \\
RI Male & $1286 \pm 25$ & & \\
\hline
\end{tabular}

GLM: Body size and robustness as covariates

Fig. 5 Femoral cortical tissue mineral density correlated negatively to body size for black women and men, white women and men, and female and male RI mice. Significant differences in the slope or $y$-intercept of the linear regressions for males and females were

body height were recorded for this osteological collection. The results of this study are limited to a cohort of individuals whose skeletal remains were archived nearly 100 years ago. Prior work compared this osteological collection and that of a modern population of healthy, military recruits and found no significant differences in tibial robustness and cortical area [26]. This comparison, although limited to white individuals, suggests that the outcomes of the current study are not limited to this collection and are worth confirming in a larger collection of individuals from diverse ethnic backgrounds.

The structural deficit observed in women compared with men is limited to the femoral diaphysis; further studies are needed to test whether similar structural deficits exist for other long bones. Because corticocancellous structures show interactions between external bone size and cortical area similar to the diaphysis [8], the current study lays the groundwork for conducting similar analyses for fractureprone sites like the proximal femur, distal radius, and spine. Sex-specific differences in tissue level mechanical properties were not measured directly but were limited to measures of tissue mineral density. Prior work using the same peripheral quantitative CT system showed significant correlations between tibial tissue mineral density and ash content and porosity [8]. Because tissue level stiffness and strength are highly correlated with ash content and porosity [6], finding

\section{White}

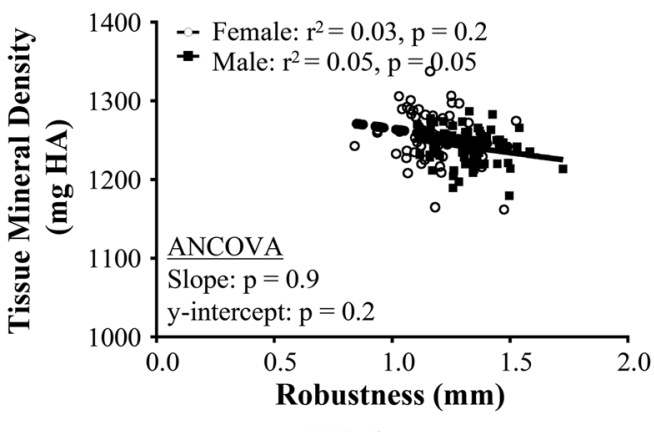

RI Mice

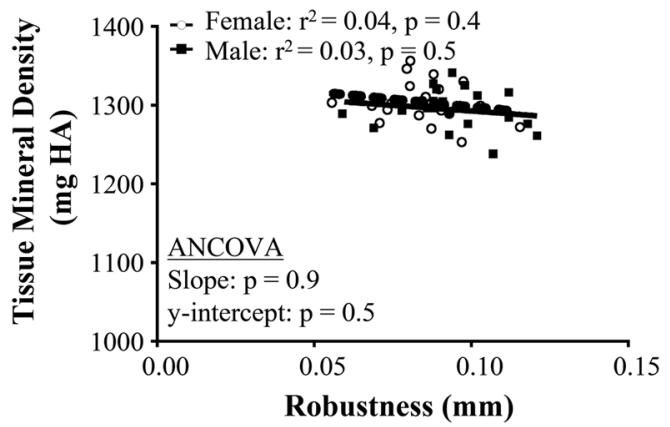

determined by ANCOVA. Results of the group mean comparison using GLM are shown (in box). Adjusted means and SDs are shown in the box. Units for tissue mineral density are in mg HA, where $\mathrm{HA}=$ hydroxyapatite. $\mathrm{RI}=$ recombinant inbred.

sex-specific differences in tissue mineral density suggests that tissue level mechanical properties are coordinately increased in female femurs in an attempt to mechanically offset the more slender morphology [9]. Prior work found no sex-specific differences in the average tissue level stiffness measured directly for the tibia of a limited cadaveric sample but did show a significant negative correlation between tissue stiffness and external bone size [32]. Thus, further studies are needed to better understand how tissue level mechanical properties differ between men and women. Finally, the analysis of inbred mice was limited to an intercross between $\mathrm{A} / \mathrm{J}$ and $\mathrm{C} 57 \mathrm{Bl} / 6 \mathrm{~J}$ inbred mouse strains. Although there is no reason to suspect that the outcome of the current study is unique to these strains, additional studies using a wider collection of inbred and outbred mouse strains are needed to confirm that female mice build stronger bones relative to body size than male mice.

Our analysis revealed that the femurs of black women had an $11 \%$ lower cortical area beyond that expected for the differences in body size and robustness. Importantly, the associations among bone morphology and body size examined in this study showed no difference in the slope of the linear regressions between black women and black men, suggesting that the sex-specific differences in bone structure were independent of whether the person was large or small. Black women had femurs with $27 \%$ less whole bone 
strength and were $6 \%$ more slender compared with black men. We showed in prior work that whole bone strength varies significantly within a healthy population with slender long bones having approximately twofold less whole bone strength compared with wider, more robust bones [13, 26]. Thus, the sex difference in whole bone strength can be explained in large part by the increased slenderness of female bones. However, the fact that the sex differences in robustness only accounted for $52 \%$ of the differences in bone strength between women and men suggested that the difference in cortical tissue mineral density was not sufficient to mechanically offset both the lesser robustness and smaller cortical area of women compared with men. Despite the deficit in cortical area found for black women relative to black men in the current study, modern black women do not show a significantly greater risk of sustaining a fragility fracture compared with black men $[3,5,33]$. The reason for this discrepancy may suggest that sex differences in robustness and cortical area found in the femoral midshaft may not necessarily mean that this mass deficit also exists for fracture prone sites like the distal radius and proximal femur. Supporting this interpretation, work by others has shown that there are no differences in hip bone mineral density between black women and men after adjusting for differences in body weight [21]. Thus, further research applying similar methodologies as those used in the current study to the proximal femur and distal radius is needed to resolve this discrepancy.

Our analysis revealed that the femurs of white women had a $12 \%$ lower cortical area, beyond that expected for the differences in body size and robustness. Prior work compared women and men of the same body size and found that women had significantly lower hip bone mineral density but had only borderline lower femoral shaft cortical area [18]. This prior study did not adjust for differences in external bone size, which we now know is important for a comparison across populations given that traits like cortical area and tissue mineral density vary naturally with external bone size [13]. The associations between bone strength index and body size, between robustness and body size, and between cortical area and body size all showed significant differences in the slope of the linear regressions between sexes. Furthermore, the lack of a significant regression in the robustness versus body size regression for white women (Fig. 3) suggests that their bones did not expand periosteally to accommodate the increased loads associated with greater body size. We reported a similar nonuniform effect for tibial strength in a more recent cohort of white men and women [13]. The nonuniform effect suggests there is a previously unrecognized subset of women who build bones with proportionally lower bone strength relative to body size. Bjornerem et al. [2] reported that taller women build wider bones that are proportionally thinner and have higher porosity. This combination of traits would be expected to lead to proportionally lower strength, consistent with the results of our study. This outcome provides support for identifying diagnostic measures of bone strength that are tailored to women and men separately. Finally, the analysis of white women and men illustrates the value of not only reporting adjusted means, but also reporting regressions among traits and testing how these associations differ between two populations (Fig. 1).

Female mice had $4 \%$ greater cortical area compared with male mice after adjusting for body size and robustness. Tremendous progress in understanding how genetic and environmental factors affect bone has been generated using the mouse as a model system [22], which has proved to be a remarkable model for replicating human skeletal morphology, growth patterns, and the way in which traits are coordinately regulated relative to the natural variation in bone width [14, 31]. Our analysis revealed that sexual dimorphism is opposite in mice compared with humans with female mice building stronger bone relative to body size compared with male mice. The greater strength of female femurs resulted from greater mass accumulation combined with higher cortical tissue mineral density relative to body size and robustness compared with males. Our data were sufficient to establish the magnitude of sex differences in these traits but provided little insight into the underlying mechanisms of why female mice build stronger bone than male mice.

In conclusion, our analysis revealed that the femurs of women are not simply a more slender version of those of men. Femurs of women were less strong relative to body size because they were more slender relative to body size, accumulated less mass and robustness than expected for body size, and did not show a disproportionately greater cortical tissue mineral density to mechanically offset the structural differences. Further work is needed to confirm these findings in more recent populations and to determine how these relationships change as a function of age. Finally, additional work is needed to establish similar functional interactions in metaphyseal structures, where fragility fractures typically occur, to determine whether similar structural deficits also occur at these sites.

Acknowledgments We thank the Glancy family for their support of this research. We also thank the Cleveland Museum of Natural History, Dr Yohannes Haile-Selassie, and Lyman Jellema for access to and assistance with the Hamann-Todd Osteological Collection.

\section{References}

1. Ahlborg HG, Johnell O, Turner CH, Rannevik G, Karlsson MK. Bone loss and bone size after menopause. $N$ Engl J Med. 2003;349:327-334.

2. Bjornerem A, Bui QM, Ghasem-Zadeh A, Hopper JL, Zebaze R, Seeman E. Fracture risk and height: an association partly 
accounted for by cortical porosity of relatively thinner cortices. $J$ Bone Miner Res. 2013;28:2017-2026.

3. Cauley JA. Defining ethnic and racial differences in osteoporosis and fragility fractures. Clin Orthop Relat Res. 2011;469:1891-1899.

4. Chen Z, Qi L, Beck TJ, Robbins J, Wu G, Lewis CE, Cauley JA, Wright NC, Seldin MF. Stronger bone correlates with African admixture in African-American women. J Bone Miner Res. 2011;26:2307-2316.

5. Cummings SR, Melton LJ. Epidemiology and outcomes of osteoporotic fractures. Lancet. 2002;359:1761-1767.

6. Currey JD. The effect of porosity and mineral content on the Young's modulus of elasticity of compact bone. J Biomech. 1988;21:131-139.

7. Duren DL, Seselj M, Froehle AW, Nahhas RW, Sherwood RJ. Skeletal growth and the changing genetic landscape during childhood and adulthood. Am J Phys Anthropol. 2013;150:48-57.

8. Epelboym Y, Gendron RN, Mayer J, Fusco J, Nasser P, Gross G, Ghillani R, Jepsen KJ. The inter-individual variation in femoral neck width is associated with the acquisition of predictable sets of morphological and tissue-quality traits and differential bone loss patterns. J Bone Miner Res. 2012;27:1501-1510.

9. Evans RK, Negus C, Antczak AJ, Yanovich R, Israeli E, Moran DS. Sex differences in parameters of bone strength in new recruits: beyond bone density. Med Sci Sports Exerc. 2008;40:S645-653.

10. Jepsen KJ. Systems analysis of bone. Wiley Interdiscip Rev Syst Biol Med. 2009;1:73-88.

11. Jepsen KJ, Akkus OJ, Majeska RJ, Nadeau JH. Hierarchical relationship between bone traits and mechanical properties in inbred mice. Mamm Genome. 2003;14:97-104.

12. Jepsen KJ, Andarawis-Puri N. The amount of periosteal apposition required to maintain bone strength during aging depends on adult bone morphology and tissue-modulus degradation rate. $J$ Bone Miner Res. 2012;27:1916-1926.

13. Jepsen KJ, Centi A, Duarte GF, Galloway K, Goldman H, Hampson N, Lappe JM, Cullen DM, Greeves J, Izard R, Nindl BC, Kraemer WJ, Negus CH, Evans RK. Biological constraints that limit compensation of a common skeletal trait variant lead to inequivalence of tibial function among healthy young adults. $J$ Bone Miner Res. 2011;26:2872-2875.

14. Jepsen KJ, Hu B, Tommasini SM, Courtland H-W, Price C, Terranova $\mathrm{CJ}$, Nadeau JH. Genetic randomization reveals functional relationships among morphologic and tissue-quality traits that contribute to bone strength and fragility. Mamm Genome. 2007;18:492-507.

15. Jepsen KJ, Pennington DE, Lee YL, Warman M, Nadeau J. Bone brittleness varies with genetic background in A/J and C57BL/6J inbred mice. J Bone Miner Res. 2001;16:1854-1862.

16. Kim BT, Mosekilde L, Duan Y, Zhang XZ, Tornvig L, Thomsen JS, Seeman E. The structural and hormonal basis of sex differences in peak appendicular bone strength in rats. $J$ Bone Miner Res. 2003;18:150-155.

17. Nguyen TV, Center JR, Sambrook PN, Eisman JA. Risk factors for proximal humerus, forearm, and wrist fractures in elderly men and women: the Dubbo Osteoporosis Epidemiology Study. Am J Epidemiol. 2001;153:587-595.

18. Nieves JW, Formica C, Ruffing J, Zion M, Garrett P, Lindsay R, Cosman F. Males have larger skeletal size and bone mass than females, despite comparable body size. J Bone Miner Res. 2005;20:529-535.

19. Pearson OM. Activity, climate, and postcranial robusticity: implications for modern human origins and scenarios of adaptive change. Curr Anthropol. 2000;41:569-607.

20. Riggs BL, Melton Iii LJ, 3rd, Robb RA, Camp JJ, Atkinson EJ, Peterson JM, Rouleau PA, McCollough CH, Bouxsein ML, Khosla S. Population-based study of age and sex differences in bone volumetric density, size, geometry, and structure at different skeletal sites. J Bone Miner Res. 2004;19:1945-1954.

21. Robbins J, Hirsch C, Cauley J. Associates of bone mineral density in older African Americans. $J$ Natl Med Assoc. 2004;96:1609-1615.

22. Rosen CJ, Beamer WG, Donahue LR. Defining the genetics of osteoporosis: using the mouse to understand man. Osteoporos Int. 2001;12:803-810.

23. Ruff CB. Body size, body shape, and long bone strength in modern humans. J Hum Evol. 2000;38:269-290.

24. Ruff CB, Trinkaus E, Walker A, Larsen CS. Postcranial robusticity in Homo. I: Temporal trends and mechanical interpretation. Am J Phys Anthropol. 1993;91:21-53.

25. Russo CR, Lauretani F, Seeman E, Bartali B, Bandinelli S, Di Iorio A, Guralnik J, Ferrucci L. Structural adaptations to bone loss in aging men and women. Bone. 2006;38:112-118.

26. Schlecht SH, Bigelow EM, Jepsen KJ. Mapping the natural variation in whole bone stiffness and strength across skeletal sites. Bone. 2014;67:15-22.

27. Schlecht SH, Jepsen KJ. Functional integration of skeletal traits: an intraskeletal assessment of bone size, mineralization, and volume covariance. Bone. 2013;56:127-138.

28. Seeman E. Clinical review 137: Sexual dimorphism in skeletal size, density, and strength. $J$ Clin Endocrinol Metab. 2001;86:4576-4584.

29. Seeman E. Periosteal bone formation-a neglected determinant of bone strength. N Engl J Med. 2003;349:320-323.

30. Selker F, Carter DR. Scaling of long bone fracture strength with animal mass. J Biomech. 1989;22:1175-1183.

31. Tommasini SM, Nasser P, Hu B, Jepsen KJ. Biological coadaptation of morphological and composition traits contributes to mechanical functionality and skeletal fragility. $J$ Bone Miner Res. 2008;23:236-246.

32. Tommasini SM, Nasser P, Jepsen KJ. Sexual dimorphism affects tibia size and shape but not tissue-level mechanical properties. Bone. 2007;40:498-505.

33. Wright NC, Saag KG, Curtis JR, Smith WK, Kilgore ML, Morrisey MA, Yun H, Zhang J, Delzell ES. Recent trends in hip fracture rates by race/ethnicity among older US adults. $J$ Bone Miner Res. 2012;27:2325-2332. 